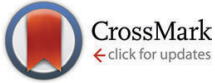

Cite this: Chem. Commun., 2016 52,3828

Received 30th November 2015, Accepted 4th February 2016

DOI: $10.1039 / c 5 c c 09873 d$

www.rsc.org/chemcomm

\section{The fabrication of formamidinium lead iodide perovskite thin films via organic cation exchange $\dagger$}

\author{
Zhongmin Zhou, Shuping Pang, * Fuxiang Ji, Bo Zhang and Guanglei Cui*
}

High-quality formamidinium lead iodide $\left(\mathrm{FAPbl}_{3}\right)$ perovskite thin films are fabricated via organic cation exchange. With ammonia lead iodide $\left(\mathrm{NH}_{4} \mathrm{Pbl}_{3}\right)$ as the starting material, the $\mathrm{NH}_{4}{ }^{+}$in $\mathrm{NH}_{4} \mathrm{Pbl}_{3}$ could be gradually substituted by $\mathrm{FA}^{+}$in formamidine acetate (FA-Ac) and simultaneously transformed to the pure phase $\alpha-\mathrm{FAPbl}_{3}$ at elevated temperature.

In recent years, perovskite solar cells have attracted tremendous attention due to its increasing light-to-electricity conversion efficiency. The efficiency record has been continuously broken, rocketing from $3.81 \%$ in $2009\left(\mathrm{CH}_{3} \mathrm{NH}_{3} \mathrm{PbI}_{3}\right.$ as the sensitizer) to $21.0 \%$ by the end of 2015 (composite perovskite as the active layer). ${ }^{1,2} \mathrm{CH}_{3} \mathrm{NH}_{3} \mathrm{PbI}_{3}\left(\mathrm{MAPbI}_{3}\right)$ is the pioneering material and plenty of deposition methods have been developed, such as the typical one-step solution deposition, ${ }^{3}$ sequential deposition, ${ }^{4}$ and other derivative techniques. ${ }^{5-10}$ Almost all these methods start with lead halide $\left(\mathrm{PbX}_{2}\right)$ and methylammonium iodide (MAI) as the precursors. ${ }^{11}$ In comparison to $\mathrm{MAPbI}_{3}$, the more recently developed $\mathrm{FAPbI}_{3}$ perovskite is less studied. The preparation of the high-quality black $\alpha-\mathrm{FAPbI}_{3}$ perovskite film is still a challenge, because the yellow $\delta$-FAPbI 3 non-perovskite polymorph phase formed from one-step solution processing at room temperature is very hard to remove. The unique crystal structure character of $\mathrm{FAPbI}_{3}$ is attributed to the larger ion size of $\mathrm{FA}^{+}$(the ionic radii of $\mathrm{FA}^{+}$and $\mathrm{MA}^{+}$are $2.79 \AA$ and $2.70 \AA$, respectively) compared to $\mathrm{MA}^{+}{ }^{12}$ Theoretically, the yellow $\delta$-FAPbI ${ }_{3}$ non-perovskite polymorph phase can transform to the photoactive black $\alpha-\mathrm{FAPbI}_{3}$ phase at elevated temperature $\left(>140{ }^{\circ} \mathrm{C}\right)$. Actually, it is not easy to for $\delta$-FAPbI ${ }_{3}$ to fully transform to $\alpha-\mathrm{FAPbI}_{3}$ when it fills the scaffold layer probably because of the stress from the substrate. ${ }^{13}$

Among all the solution processing methods, the sequential deposition method can directly lead to the $\alpha-\mathrm{FAPbI}_{3}$ phase, but

Qingdao Institute of Bioenergy and Bioprocess Technology, Chinese Academy of Sciences, Qingdao 266101, People's Republic of China.

E-mail: pangsp@qibebt.ac.cn, cuigl@qibebt.ac.cn; Tel: +86-5328066-2746

$\dagger$ Electronic supplementary information (ESI) available: Experimental details and Fig. S1-S6 and Table S1. See DOI: 10.1039/c5cc09873d it always produces a large surface roughness because of the volume expansion behaviour and also results in the formation of some unreacted $\mathrm{PbI}_{2}$ residues, ${ }^{14}$ which dramatically decrease the stability of the devices. ${ }^{15}$ The recently developed intramolecular exchange strategy by replacing the dimethylsulfoxide (DMSO) molecule with formamidinium iodide (FAI) from the DMSO-PbI complex can directly produce full coverage $\alpha-\mathrm{FAPbI}_{3}$ films, ${ }^{2}$ implying that molecule or even ion exchange may be a promising direction for the direct synthesis of $\alpha-\mathrm{FAPbI}_{3}$ without the formation of the yellow $\delta$-FAPbI ${ }_{3}$ non-perovskite polymorph.

In this communication, we presented an organic cation exchange method to directly grow $\alpha-\mathrm{FAPbI}_{3}$ perovskite films, using $\mathrm{NH}_{4} \mathrm{PbI}_{3}$ and FA-Ac as precursors using the CVD technique. $\mathrm{NH}_{4} \mathrm{PbI}_{3}$ is selected as the precursor for its high solubility in $N, N$-dimethylformamide (DMF). The organic cation exchange process is schematically depicted in Fig. 1. An equimolar amount of $\mathrm{PbI}_{2}$ and $\mathrm{NH}_{4} \mathrm{I}$ was firstly dissolved in DMF. Then the precursors were spin-coated onto the as-prepared substrate. These as-obtained films were put into the upper center of the CVD tube furnace, while FA-Ac was placed just under the films. Then the quartz tube was evacuated to under $10^{-2} \mathrm{~Pa}$, and at the same time heated up to $160{ }^{\circ} \mathrm{C}$. The black $\alpha$-FAPbI ${ }_{3}$ polymorph phase was obtained during the exchange process between $\mathrm{FA}^{+}$and $\mathrm{NH}_{4}{ }^{+} \cdot \mathrm{NH}_{4} \mathrm{Ac}$ as the product of cation exchange is more volatile than FA-Ac, which is beneficial for the occurrence of the cation exchange.

The crystal structure of the $\mathrm{NH}_{4} \mathrm{PbI}_{3}$ has been confirmed by X-ray diffraction (XRD) measurements. Fig. 2A shows the indexed XRD pattern deposited on the FTO/compact

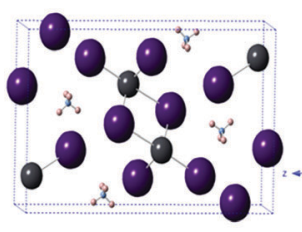

$\mathrm{NH}_{4} \mathrm{Pbl}_{3}$

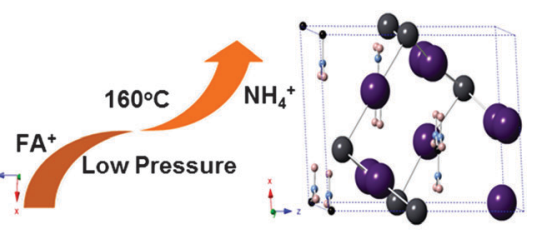

$\alpha-\mathrm{FAPbl}_{3}$
Fig. 1 Schematic illustration of the proposed cation exchange process. 


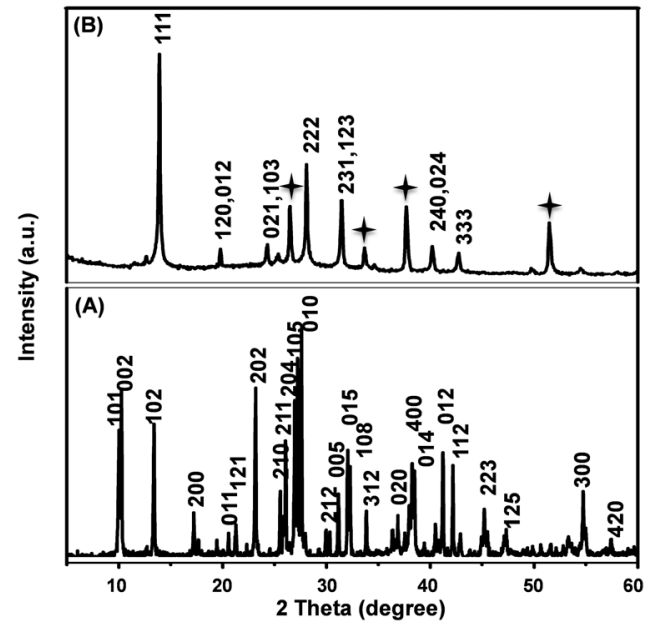

Fig. 2 XRD patterns of (A) $\mathrm{NH}_{4} \mathrm{Pbl}_{3}$ and (B) $\mathrm{FAPbl}_{3}$ films on the $\mathrm{FTO} / \mathrm{c}-\mathrm{TiO}_{2} / \mathrm{mp}-\mathrm{TiO}_{2}$ substrate.

(c)- $-\mathrm{TiO}_{2} /$ mesoporous(mp)- $\mathrm{TiO}_{2}$ substrate. Rietveld refinement analysis of the $\mathrm{X}$-ray powder diffraction pattern indicates that the synthesized $\mathrm{NH}_{4} \mathrm{PbI}_{3}$ has the lattice parameters of $a=10.308 \AA$, $b=4.378 \AA$, and $c=17.281 \AA$, with the space group of Pmn21, which is in good agreement with the reported results. ${ }^{16}$

The structure of $\alpha-\mathrm{FAPbI}_{3}$ was confirmed by XRD and UV-vis absorption measurements. All the peaks are in good agreement with those reported for $\alpha-\mathrm{FAPbI}_{3} .{ }^{17}$ It shows that the as-prepared $\alpha$-FAPbI ${ }_{3}$ film has a very strong (111) orientation diffraction peak at $13.8^{\circ}$ in comparison with the $\alpha-\mathrm{FAPbI}_{3}$ powder sample. ${ }^{17}$ The UV-vis absorption spectra of the $\mathrm{NH}_{4} \mathrm{PbI}_{3}$ film and the film after the cation exchange process are presented in Fig. 3. They show the total absorption in the visible spectral range for the film after the reaction. The linear fits of the absorption edge of the as-synthesized $\alpha-\mathrm{FAPbI}_{3}$ film indicate that the absorption onset is $c a .840 \mathrm{~nm}$, corresponding to a bandgap of $1.47 \mathrm{eV}$, which is close to that of the $\alpha-\mathrm{FAPbI}_{3}$ film synthesized by the two-step dipping method. ${ }^{18}$ Compared to the $1.55 \mathrm{eV}$ bandgap for $\mathrm{MAPbI}_{3}$, the bandgap of $\alpha-\mathrm{FAPbI}_{3}$ is closer to the ideal bandgap for single-junction solar cells. ${ }^{19}$

In order to gain insight into the cation exchange process, Fourier transform infrared spectroscopy (FTIR) was used to

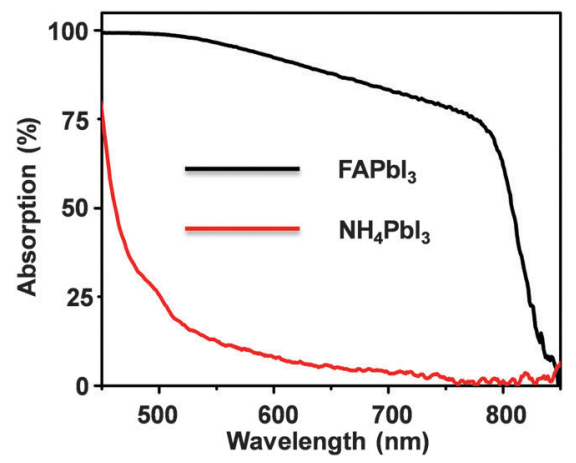

Fig. 3 UV-vis absorbance spectra of $\mathrm{NH}_{4} \mathrm{Pbl}_{3}$ and $\alpha$-FAPb| films on the mesoporous $-\mathrm{TiO}_{2}$ scaffold.

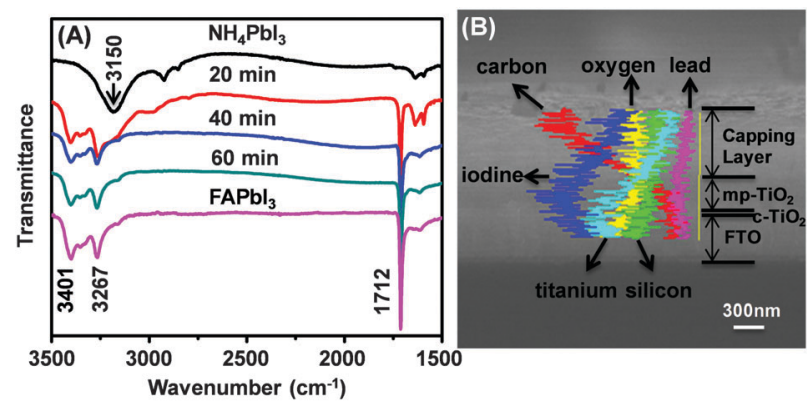

Fig. 4 (A) FTIR spectra of the prepared films with the cation exchange process for 20-60 min, and the standard $\mathrm{FAPb}_{3}$ sample, respectively. (B) SEM cross-sectional image and the EDX of an incompletely transformed $\mathrm{FAPbl}_{3}$ film.

investigate the as-obtained film with different reaction times (Fig. 4A). No new stretching vibration peak of $\mathrm{Ac}^{-}\left(1540-1620 \mathrm{~cm}^{-1}\right)$ during the whole reaction process was observed, ${ }^{20}$ which indicates that the $\mathrm{Ac}^{-}$could not insert into the film and the cation exchange probably happens only on the film surface. We can see that a strong stretching vibration of $\mathrm{C}=\mathrm{N}$ from $\mathrm{FA}^{+}$ appears at $1712 \mathrm{~cm}^{-1}$ when the reaction proceeds for $20 \mathrm{~min}$. At the same time, two other peaks at $3267 \mathrm{~cm}^{-1}$ and $3401 \mathrm{~cm}^{-1}$ appear, which belong to the stretching vibrations of $\mathrm{N}-\mathrm{H}$ for $\mathrm{FA}^{+}$. In addition, the stretching vibration of $\mathrm{N}-\mathrm{H}$ for $\mathrm{NH}_{4}{ }^{+}$at $3150 \mathrm{~cm}^{-1}$ almost disappears at $40 \mathrm{~min}$. This FTIR spectrum is similar to that of the standard $\mathrm{FAPbI}_{3}$ perovskite film. ${ }^{21}$ The absorption peaks indicate that the cation exchange process was complete at $\sim 40 \mathrm{~min}$ and no more $\mathrm{FA}^{+}$could be inserted into the starting film by extending the reaction time.

To clearly check the gradual change of composition during the ion exchange reaction, a thicker $\mathrm{NH}_{4} \mathrm{PbI}_{3}$ film was deposited for the cross-sectional measurements. The energy-dispersive X-ray (EDX) spectra of the film after the reaction proceeded for 10 min are shown in Fig. 4B. Two elements which change more obviously are carbon and iodine. There is no carbon in the $\mathrm{NH}_{4} \mathrm{PbI}_{3}$ precursor film; therefore, the appearance of carbon is attributed to the replacement of $\mathrm{NH}_{4}{ }^{+}$with $\mathrm{FA}^{+}$. The high concentration of $\mathrm{FA}^{+}$near the surface further indicates that the substitution of $\mathrm{NH}_{4}^{+}$with $\mathrm{FA}^{+}$occurs at the film surface. Compared with the carbon element, the opposite trend of iodine in the film is because of the relatively high iodine concentration in $\mathrm{NH}_{4} \mathrm{PbI}_{3}$ compared with that in $\mathrm{FAPbI}_{3}{ }^{16,17}$ Based on the above analysis, we can surmise that the cation exchange between $\mathrm{FA}^{+}$and $\mathrm{NH}_{4}{ }^{+}$occurs at the film surface, then the $\mathrm{FA}^{+}$ions could diffuse inside and the $\mathrm{NH}_{4}{ }^{+}$ions diffuse to the surface and sequentially exchange with $\mathrm{FA}^{+}$. The inside diffusion and surface ion exchange are carried out simultaneously until all the $\mathrm{NH}_{4}{ }^{+}$ ions are exchanged with $\mathrm{FA}^{+}$ions.

Solar cells based on the as-prepared $\alpha-\mathrm{FAPbI}_{3}$ were constructed using $\mathrm{mp}-\mathrm{TiO}_{2}$ as the electron transport layer and $2,2^{\prime}, 7,7^{\prime}$-tetrakis( $N, N$-di- $p$-methoxyphenylamine)-9, $9^{\prime}$-spiro-biofluorine (spiroOMeTAD) as the hole transport layer (Fig. 5A). Dense, uniform and black films are obtained at $160{ }^{\circ} \mathrm{C}$ for a reaction time of $60 \mathrm{~min}$ as can be seen from the scanning electron microscopy (SEM) image in Fig. 5B. The AFM topographical image 

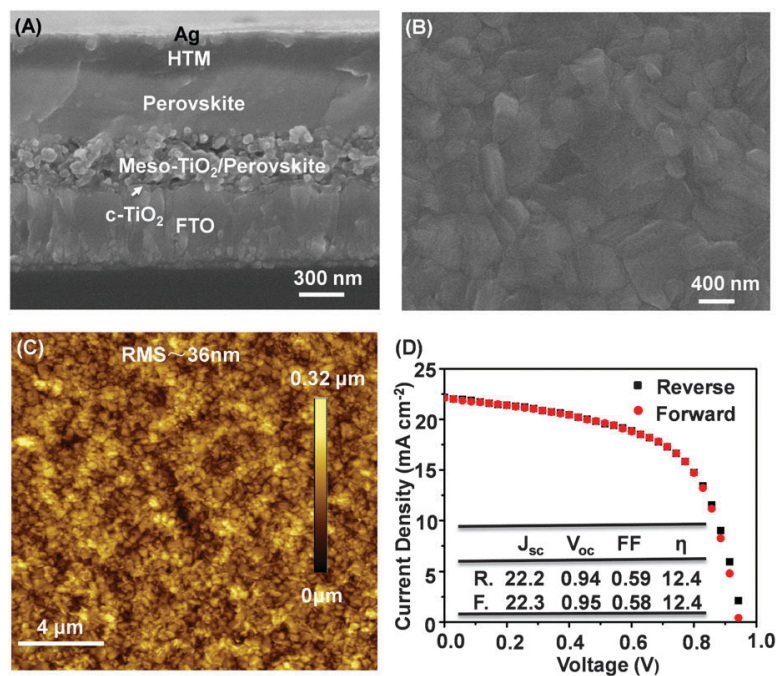

Fig. 5 (A) Cross-sectional SEM image of a complete perovskite device composed of FTO, compact blocking layer $\mathrm{TiO}_{2}$, mesoporous- $\mathrm{TiO}_{2}$, the perovskite film, a hole transporting layer (Spiro-MeOTAD), and a silver top electrode. (B) SEM images of the FAPbl 3 perovskite film. (C) AFM image of the top surfaces of the $\mathrm{FAPb}_{3}$ film. (D) $J-V$ characteristics of a $\mathrm{FAPbl}_{3}$ champion device. Inset shows the detailed photovoltaic parameters.

$\left(20 \times 20 \mu \mathrm{m}^{2}\right)$ of the $\alpha-\mathrm{FAPbI}_{3}$ reveals a root mean square (RMS) roughness of approximately $36 \mathrm{~nm}$ (Fig. 5C). The photocurrent density as a function of bias voltage is measured under standard AM 1.5 sunlight at a humidity of about $30 \%$. Fig. 5D shows the values of the champion device with the reverse scanning direction (from the open-circuit voltage $\left(V_{\mathrm{oc}}\right)$ to the short-circuit current $\left.\left(J_{\mathrm{sc}}\right)\right)$ and forward scanning direction (from $J_{\text {sc }}$ to $V_{\text {oc }}$ ). The device exhibits an efficiency of $12.4 \%$ with no hysteresis. The statistics of PCEs are presented in Fig. S1 (ESI $\dagger$ ), showing the high reproducibility of the cation exchange method. For comparison, the $\mathrm{FAPbI}_{3}$ and $\mathrm{MAPbI}_{3}$ devices are also fabricated and measured as shown in Fig. S2 and Table S1 (ESI $\dagger$ ), indicating that the proposed cation exchange method is a viable approach towards preparation of high-quality $\mathrm{FAPbI}_{3}$ perovskite films.

Other than the extended light absorbance range, the $\alpha-\mathrm{FAPbI}_{3}$ film also delivers an improved thermal stability. Fig. 6 shows the thermal stability comparison between the $\alpha-\mathrm{FAPI}_{3}$ and $\mathrm{MAPbI}_{3}$ films. Both of the films were obtained using the CVD method (the preparation procedure of the films of $\mathrm{MAPbI}_{3}$ can be seen in the ESI $\dagger$ ). A series of $\alpha-\mathrm{FAPbI}_{3}$ and $\mathrm{MAPbI}_{3}$ films (without HTM and electrodes) were heated at $140{ }^{\circ} \mathrm{C}$ in an argon-filled glove box for 1-7 h. Then the corresponding devices were assembled and studied. The PCEs of $\alpha$-FAPbI ${ }_{3}$-based cells decreased only $\mathrm{ca}$. 5\% when the perovskite film was heated to $140{ }^{\circ} \mathrm{C}$ for up to $7 \mathrm{~h}$, while the $\mathrm{MAPbI}_{3}$-based devices decrease to ca. $11 \%$ after heating for $4 \mathrm{~h}$ and to zero after heating for $6 \mathrm{~h}$. As shown in Fig. S3 (ESI $\dagger$ ), the $\mathrm{MAPbI}_{3}$ phase begins to decay after heating for $4 \mathrm{~h}$ and completely decomposed after heating for $7 \mathrm{~h}$. However, the colour of the $\alpha-\mathrm{FAPbI}_{3}$ film stays almost the same even after heating for $7 \mathrm{~h}$. The SEM images in Fig. 6(B, C) and Fig. S4 (ESI $\dagger$ ) show the change of the morphology of the films

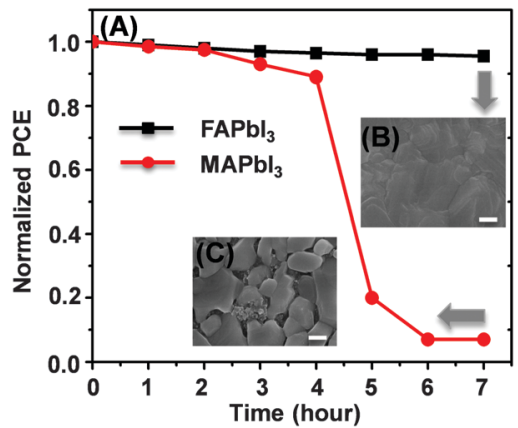

Fig. 6 (A) Normalized PCE evolution based on $\alpha-\mathrm{FAPb}_{3}$ and $\mathrm{MAPb}_{3}$ films annealed at $140{ }^{\circ} \mathrm{C}$ for $0-7 \mathrm{~h}$. (B and C) SEM images of the $\mathrm{FAPbl}_{3}$ and $\mathrm{MAPb}_{3}$ films heated for $7 \mathrm{~h}$. The scale bar is $200 \mathrm{~nm}$.

before and after long-time heating treatment. In contrast to the stable $\alpha-\mathrm{FAPbI}_{3}$, the $\mathrm{MAPbI}_{3}$ films obviously shrink after heating for $7 \mathrm{~h}$.

Moreover, the presented cation exchange method was also performed on $\mathrm{HPbI}_{3}$ and $\mathrm{MAPbI}_{3}$ films. $\mathrm{HPbI}_{3}$ was prepared according to a reported procedure, ${ }^{22}$ and the preparation procedure of $\mathrm{MAPbI}_{3}$ films can be seen in the ESI. $\dagger$ The XRD patterns (Fig. S5, ESI $\dagger$ ) and the UV-vis absorption spectra (Fig. S6, ESI $\dagger$ ) strongly confirm the successful fabrication of the $\mathrm{FAPbI}_{3}$ films.

In conclusion, we have demonstrated an organic cation exchange concept for the preparation of high-quality $\alpha-\mathrm{FAPbI}_{3}$ films using the CVD method. The PCE of the champion device was $12.4 \%$ based on the mesoscopic structure with no hysteresis. We also demonstrated that this cation exchange concept could also be used to prepare $\alpha-\mathrm{FAPbI}_{3}$ thin films by replacing $\mathrm{H}^{+}$and $\mathrm{MA}^{+}$in $\mathrm{HPbI}_{3}$ and $\mathrm{MAPbI}_{3}$ with $\mathrm{FA}^{+}$. This concept will be an alternative route for the development of highly efficient $\mathrm{FAPbI}_{3}$ solar cells.

The financial support of this research by the International S\&T Cooperation Program of China (2015DFG62670), the Chinese National Natural Science Foundation (51302279), the China Postdoctoral Science Foundation (2015M582156), the Basic Research Program of Qingdao (14-2-4-8-jch), and the Qingdao Key Lab, for solar energy utilization and energy storage technology, is greatly acknowledged.

\section{Notes and references}

1 A. Kojima, K. Teshima, Y. Shirai and T. Miyasaka, J. Am. Chem. Soc., 2009, 131, 6050-6051.

2 NREL, www.nrel.gov/ncpv/images/efficiency_chart.jpg, 2015.

3 H. S. Kim, C. R. Lee, J. H. Im, K. B. Lee, T. Moehl, A. Archioro, S. J. Moon, R. Humphry-Baker, J. H. Yum, J. E. Moser, M. Grätzel and N. G. Park, Sci. Rep., 2012, 2, 591.

4 J. Burschka, N. Pellet, S. J. Moon, R. Humphry-Baker, P. Gao, M. K. Nazeeruddin and M. Grätzel, Nature, 2013, 499, 316-319.

5 M. Liu, M. B. Johnston and H. J. Snaith, Nature, 2013, 501, 395-398.

6 Q. Chen, H. Zhou, Z. Hong, S. Luo, H. S. Duan, H. H. Wang, Y. Liu, G. Li and Y. Yang, J. Am. Chem. Soc., 2014, 136, 622-625.

7 S. Ahmad, P. K. Kanaujia, W. Niu, J. J. Baumberg and G. V. Prakash, ACS Appl. Mater. Interfaces, 2014, 6, 10238-10247.

8 M. Xiao, F. Huang, W. Huang, Y. Dkhissi, Y. Zhu, J. Etheridge, A. Gray-Weale, U. Bach, Y. B. Cheng and L. Spiccia, Angew. Chem., Int. Ed., 2014, 53, 9898-9909. 
9 A. Mei, X. Li, L. Liu, Z. Ku, T. Liu, Y. Rong, M. Xu, M. Hu, J. Chen, Y. Yang, M. Grätzel and H. Han, Science, 2014, 345, 295-298.

10 K. Hwang, Y. S. Jung, Y. J. Heo, F. H. Scholes, S. E. Watkins, J. Subbiah, D. J. Jones, D. Y. Kim and D. Vak, Adv. Mater., 2015, 27, 1241-1247.

11 P. Gao, M. Grätzel and M. K. Nazeeruddin, Energy Environ. Sci., 2014, 7, 2448-2463.

12 A. Binek, F. C. Hanusch, P. Docampo and T. Bein, J. Phys. Chem. Lett., 2015, 6, 1249-1253.

13 Z. Wang, Y. Zhou, S. Pang, Z. Xiao, J. Zhang, W. Chai, H. Xu, Z. Liu, N. P. Padture and G. Cui, Chem. Mater., 2015, 27, 7149-7155.

14 L. Hu, J. Peng, W. Wang, Z. Xia, J. Yuan, J. Lu, X. Huang, W. Ma, H. Song, W. Chen, Y. B. Cheng and J. Tang, ACS Photonics, 2014, 1, 547-553.

15 F. Liu, Q. Dong, M. K. Wong, A. B. Djurišic, A. Ng, Z. Ren, Q. Shen, C. Surya, W. K. Chan, J. Wang, A. M. C. Ng, C. Liao, H. Li, K. Shih, C. Wei, H. Su and J. Dai, Adv. Energy Mater., 2016, 1502206.
16 L. Q. Fan and J. H. Wu, Acta Crystallogr., 2007, E63, i189.

17 S. Pang, H. Hu, J. Zhang, S. Lv, Y. Yu, F. Wei, T. Qin, H. Xu, Z. Liu and G. Cui, Chem. Mater., 2014, 26, 1485-1491.

18 T. M. Koh, K. Fu, Y. Fang, S. Chen, T. C. Sum, N. Mathews, S. G. Mhaisalkar, P. P. Boix and T. Baikie, J. Phys. Chem. C, 2014, 118, 16458-16462.

19 G. E. Eperon, S. D. Stranks, C. Menelaou, M. B. Johnston, L. M. Herz and H. J. Snaith, Energy Environ. Sci., 2014, 7, 982-988.

20 M. Luo, P. Guan and W. Liu, Spectrosc. Spectral Anal., 2007, 27, 250-253.

21 S. Wozny, M. Yang, A. M. Nardes, C. C. Mercado, S. Ferrere, M. O. Reese, W. Zhou and K. Zhu, Chem. Mater., 2015, 27, 4814-4820.

22 F. Wang, H. Yu, H. Xu and N. Zhao, Adv. Funct. Mater., 2015, 25, 1120-1126. 